\section{Response from the authors}

Dear Sir,

We are certainly familiar with the study by Frayn et al. [1] and their promising technique in measuring arteriovenous differences over the abdominal subcutaneous wall. However, one advantage with the microdialysis technique as compared to a-v measurements is that the interstitial fluid of the subcutaneous tissue reflects fat cell metabolism without the contamination of skin lactate production. We are also aware of the fact that the blood lactate is lower than plasma lactate. However, lactate production in adipose tissue averages $\sim 1 \mu \mathrm{mol} / 100 \mathrm{~g}$ tissue which is a high production rate. In contrast, Frayn et al. stated that the lactate production in the adipose tissue is low. Thus, even though the plasma lactate levels in our study [2] and that of Frayn et al. [1] seem to be comparable the conclusions are obviously different since the lactate concentration in the extracellular water indicates that adipose tissue is an important source of production [2]. In our article we also clearly state that distinct quantifications cannot be made since the blood flow was not measured. [2] However, we have now added blood flow measurements to the microdialysis procedure which will allow more precise information. Since we have not measured lipoprotein exchange we cannot comment on the results referred to by Drs. Frayn and Coppack. However, the microdialysis technique certainly allows measurements of fairly large molecules.

Yours sincerely,

P.-A.Jansson, U.Smith and P.Lönnroth

\section{References}

1. Frayn KN, Coppack SW, Humphreys SM, Whyte PL (1989) Metabolic characteristics of human adipose tissue in vivo. Clin Sci 76 : 506-516

2. Iannsson P-A, Smith U, Lönnroth P (1990) Evidence for lactate production by human adipose tissue in vivo. Diabetologia 33: 253 256

U.Smith, M.D., Ph. D.

Department of Medicine

Göteborgs Universitet

Sahlgrenska sjukhuset

S-413 45 Göteborg

Sweden

\section{Immunotherapy in pre-Type 1 diabetes mellitus}

\section{Dear Sir,}

During the past decade a large body of data has accumulated implicating autoimmunity in the pathogenesis of Type 1 diabetes. This has prompted research trials of immunotherapy to prevent ongoing Beta-cell destruction [1-3]. However, the effectiveness of immunotherapy initiated after the onset of clinical diabetes is limited by the extent of Beta-cell destruction which has occurred by this stage [4]. The ability to predict Type 1 diabetes in the pre-clinical stage by the combination of genetic (HLA typing), immunological (islet and insulin autoantibodies) and metabolic (first phase insulin secretion to intravenous glucose) markers, sets the scene for therapeutic intervention during the evolution of the autoimmune disease process when Beta-cell destruction is only partial [5-7]. Trials of potential therapies in this pre-clinical stage have been initiated in the USA, West Germany, Italy and New Zealand. Despite the potential to prevent a disease that may have considerable morbidity and mortality, therapeutic trials in pre-diabetic patients must be carefully controlled because the sensitivity, specificity and precision of the predictive markers are still not properly established. Such trials should therefore include randomization as well as placebo blinding where applicable. They should only be undertaken with informed consent and with oversight of Human Committees by investigators with experience in assessing the predictive markers of Type 1 diabetes and the potential therapies to be employed. Therapies aimed at the prevention of Type 1 diabetes should not be administered until control trials establish their efficacy and safety.

Yours sincerely,

J.F. Bach, J.Dupré, G. S. Eisenbarth, L. C. Harrison, N. K. Maclaren, J. Nerup and P. Pozzilli for the International Immunotherapy Group

\section{References}

1. Canadian-European Randomized Control Trial Group (1988) Cyclosporin-induced remission of IDDM after early intervention: association of 1 year of cyclosporin treatment with enhanced insulin secretion. Diabetes 37:1574-1582

2. Bougneres PF, Carel JC, Castano L, Boitard C, Gardin JP, Landais P, Hors J, Mihatsch MJ, Paillard M, Chaussain JL, Bach JF (1988) Factors associated with early remission of type 1 diabetes in children treated with cyclosporine. N Engl J Med 318: 636-670

3. Silverstein J, Maclaren NK, Riley W, Spillar R, Radjenovic D, Johnson S (1988) Immunosuppression with azathioprine and prednisone in recent-onset insulin-dependent diabetes mellitus. $\mathrm{N}$ Engl J Med 319: 599-604

4. Andreani D, Kolb H, Pozzilli P (1989) In: Immunotherapy of Type 1 diabetes. Wiley \& Sons, Chichester, pp 195-220

5. Srikanta S, Ganda OP, Rabizadeh A, Soeldner JS, Eisenbarth GS (1985) First degree relatives of patients with Type 1 diabetes mellitus: islet cell antibodies and normal insulin secretion. N Engl J Med 313: 461-464

6. Tarn A, Thomas JC, Dean BM, Ingram D, Schwarz G, Bottazzo GF, Gale EAM (1988) Predicting insulin dependent diabetes. Lancet I: $845-850$

7. Cook JJ, Hudson I, Harrison LC, Dean B, Colman PG, Werther GA, Warne GL, Court JM (1989) A double-blind controlled trial of azathioprine in children with newly-diagnosed type 1 diabetes. Diabetes 38: 779-783

Dr. P.Pozzilli

IDIG Secretariat and Registry

PO Box 680

I-00187 Rome

Italy 